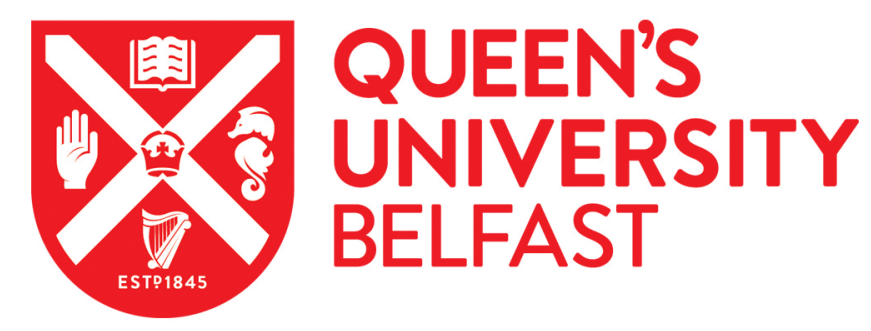

\title{
Quantitative Studies of the Coverage Effects on Microkinetic Simulations for NO Oxidation on Pt(111)
}

Ding, Y., Xu, Y., Song, Y., Guo, C., \& Hu, P. (2019). Quantitative Studies of the Coverage Effects on

Microkinetic Simulations for NO Oxidation on Pt(111). The Journal of Physical Chemistry C, 123(45), 2759427602. https://doi.org/10.1021/acs.jpcc.9b08208

\section{Published in:}

The Journal of Physical Chemistry C

\section{Document Version:}

Peer reviewed version

Queen's University Belfast - Research Portal:

Link to publication record in Queen's University Belfast Research Portal

\section{Publisher rights}

(C) 2019 American Chemical Society. This work is made available online in accordance with the publisher's policies. Please refer to any applicable terms of use of the publisher.

\section{General rights}

Copyright for the publications made accessible via the Queen's University Belfast Research Portal is retained by the author(s) and / or other copyright owners and it is a condition of accessing these publications that users recognise and abide by the legal requirements associated with these rights.

Take down policy

The Research Portal is Queen's institutional repository that provides access to Queen's research output. Every effort has been made to ensure that content in the Research Portal does not infringe any person's rights, or applicable UK laws. If you discover content in the Research Portal that you believe breaches copyright or violates any law, please contact openaccess@qub.ac.uk. 


\title{
Quantitative Studies of the Coverage Effects on Microkinetic Simulations for NO Oxidation on $\operatorname{Pt}(111)$
}

\author{
Yunxuan Ding, ${ }^{\dagger}$ Yarong Xu, ${ }^{\dagger,+}$ Yihui Song, ${ }^{\dagger}$ Chenxi Guo ${ }^{\dagger, \xi}$ and P. Hu*广 \\ †School of Chemistry and Chemical Engineering, The Queen’s University of Belfast, \\ Belfast, BT9 5AG, UK. \\ †Research Institute of Urumqi Petrochina Chemical Company, Changchun South \\ Road 466, Urumqi 830011, People's Republic of China
}

${ }^{\S}$ State Key Laboratory of Catalysis, Dalian Institute of Chemical Physics, Chinese Academy of Sciences, Zhongshan Road 457, Dalian 116023, People’s Republic of China

\begin{abstract}
To advance a reliable microkinetic modeling approach using density functional theory (DFT) energies is of great importance to bridging between experimental results and theoretical calculations and the current major issue is the coverage effect. In this work, a full microkinetic modeling for NO oxidation using DFT energetics is developed. We show that the calculated TOF $\left(0.22 \mathrm{~s}^{-1}\right)$ agrees with the experimental one $\left(\sim 0.2 \mathrm{~s}^{-1}\right)$ very well, if the coverage effects are properly incorporated. It is found
\end{abstract}


that to include the interactions of adsorbates, namely (i) $\mathrm{O}$ and $\mathrm{O}, \mathrm{NO}$ and $\mathrm{NO}$ (self-interaction) and (ii) $\mathrm{O}$ and NO (cross-interaction), is important to obtain accurate kinetic results. Equally important, the interactions between the adsorbates and the transition states of $\mathrm{O}-\mathrm{O}$ bond breaking and $\mathrm{O}-\mathrm{NO}$ coupling are also crucial for achieving precise kinetics. We demonstrate that a two-line model can be used to describe accurately both the self and cross adsorbate-adsorbate interactions as well as the coverage effects on the transition states of $\mathrm{O}_{2}$ dissociation and $\mathrm{O}-\mathrm{NO}$ coupling. The various approximations including BEP relations are carefully examined and the errors involved are quantified. Moreover, a one-line model is tested, which is a simplified approach but gives rise to a good agreement with experimental results.

\section{Introduction}

Nitrogen oxides $\left(\mathrm{NO}_{\mathrm{x}}\right)$ emitted from the usage of the fossil fuel is gaining global attentions due to the increasing demand of the environmental protection ${ }^{1,2}$. However, the conventional three-way catalyst (TWC) converters for diesel engines cannot efficiently convert $\mathrm{NO}_{\mathrm{x}}$ to $\mathrm{N}_{2}$ because of the excess of air ${ }^{3,4}$, and thus a high-efficiency way to remove the $\mathrm{NO}_{\mathrm{x}}$ exhaust is urgently needed. There are several $\mathrm{NO}_{\mathrm{x}}$ abatement technologies ${ }^{5-7}$ to solve this problem. As an important intermediate species in the lean-burn cycles of the $\mathrm{NO}_{\mathrm{x}}$ storage-reduction $(\mathrm{NSR})^{4,8,9}$, the nitric oxide (NO) and nitrogen dioxide $\left(\mathrm{NO}_{2}\right)$ can help achieve an acceptable level of $\mathrm{NO}_{\mathrm{x}}$ storage. The selective catalytic reduction (SCR) with $\mathrm{NH}_{3}$ is also an efficient method to remove $\mathrm{NO}_{\mathrm{x}}$, which has high activity with the addition of $\mathrm{NO}_{2}^{2,10,11}$. In these 
technologies, the oxidation of $\mathrm{NO}$ to $\mathrm{NO}_{2}$ plays a crucial role in reducing the effect caused by air pollution from $\mathrm{NO}_{\mathrm{x}}{ }^{12,13}$.

As an important catalytic reaction, NO oxidation has been widely studied both experimentally and theoretically. Wang and co-workers found the Mn-mullite (Sm, Gd) $\mathrm{Mn}_{2} \mathrm{O}_{5}$ to be an efficient catalyst for $\mathrm{NO}$ oxidation with low temperature and high conversion rate ${ }^{14}$. Balakotaiah and co-workers reported the kinetics of NO oxidation over $\mathrm{Pt} / \mathrm{Al}_{2} \mathrm{O}_{3}$ and $\mathrm{Pt} / \mathrm{BaO} / \mathrm{Al}_{2} \mathrm{O}_{3}$, and observed that the surface was mainly covered by oxygen $(\mathrm{O})$ and $\mathrm{NO}^{15}$. Moreover, $\mathrm{NO}$ oxidation is also studied on metal ${ }^{8,16-20}$, perovskite $^{21,22}$ and metal oxides ${ }^{23-25}$. Our group carried out a series of works on NO oxidation using density functional theory $(\mathrm{DFT})^{9,26,27}$. The activity trend of NO oxidation on several of metals ${ }^{9}$ and metal oxides ${ }^{26}$ was studied. It was discovered that NO oxidation may occur on $\mathrm{Cr}_{2} \mathrm{O}_{3}$ catalysts even at room temperature ${ }^{27}$.

With the development of microkinetics modeling ${ }^{28,29}$, the reaction activity can be estimated quantitatively using the reaction barriers and the reaction energies from DFT calculations ${ }^{30}$, which can build a bridge between the experiments and the computational calculations. However, the reaction rates were often calculated to be quantitatively far away from experiment results $^{31}$. In contrast to typical kinetic simulations using the energies at low coverages of adsorbates on the surface in the previous works $9,32,33$, the real catalytic systems are more complex with the lateral interactions under experimental conditions ${ }^{34,35}$, in which the coverage can have large effects on kinetic results. To carry out coverage-dependent kinetic calculations, the adsorbate-adsorbate interactions should be taken into account ${ }^{36-39}$. 
In previous work, the self-interaction, namely the interaction between species of the same kind, has already been investigated. Several studies reported that the adsorption energies remained constant in the low coverage region and became weaker as the coverage increase in the high coverage region ${ }^{36,38}$. They noticed not only the self-interaction, but also the cross-interaction (the interaction between different kinds of adsorption species) existing in the reaction. Some approximate methods were put forward to describe the cross-interaction ${ }^{36,38}$. In addition to the coverage-dependent adsorption energies, the reaction barriers are also needed to be calculated with the coverage effect for the reaction rates using microkinetics modeling. Several methods were proposed to estimate the reaction barriers: Firstly, based on the linear relationship between the adsorption energies and the reaction barriers of different metals, the so-called Brønsted-Evans-Polanyi (BEP) relation ${ }^{40-42}$, the reaction barriers can be estimated by the adsorption energies with coverage effects. Schneider and co-workers ${ }^{37,43}$ reported a detailed kinetic study on NO oxidation using the grand canonical Monte Carlo simulations associating with the cluster expansion to obtain the accurate adsorbate-adsorbate interactions. With the utilization of BEP relation and the neglection of the coverages of other species except oxygen, their reaction rate of NO oxidation was in good agreement with the experiment ${ }^{44}$. Secondly, an approximate method was reported to correct the reaction barriers by applying different weights on the initial and final states as a function of the coverage-dependent adsorption energies ${ }^{45}$. It is clear that more detailed investigations are desirable in the field. 
In this work, the self and cross adsorbate-adsorbate interactions are systematically investigated. In addition, the interaction between the transition state (TS) and adsorbate, namely the TS energies as a function of adsorbate coverages, are rigorously calculated. The $\mathrm{Pt}(111)$ surface is chosen to study the microkinetics of NO oxidation with the coverage-dependent effects for several reasons: Firstly, Pt is commonly used for NO oxidation industrially with its high red-ox activity ${ }^{8,46}$. Secondly, several experimental results have been reported ${ }^{31,34}$, with the TOF to be $\sim 0.2 \mathrm{~s}^{-1}$, which can be used as a benchmark to compare with theoretical results. Thirdly, NO oxidation on $\operatorname{Pt}(111)$ is observed to have the similar apparent activation energies and rate orders to the experimental supported Pt catalysts ${ }^{31}$. An accurate kinetic result using DFT energies is obtained compared to the experimental data. A detailed analysis is carried out and a one-line model is derived, which shows excellent agreement with experiment results.

\section{Computation details}

In this work, all the DFT calculations were performed with the Vienna Ab-initio Simulation Package (VASP) in the periodic slab model ${ }^{47,48}$. The electronic structures were calculated using the generalized gradient approximation (GGA) with the Perdew-Burke-Ernzerhof (PBE) functional ${ }^{49}$, while the ionic cores were described by the projector-augmented wave $(\mathrm{PAW})$ potentials ${ }^{48,50} \cdot \mathrm{Pt}(111)$ which is the most stable surface was chosen to be the catalytic active surface with a periodic slab consisting of 4-layers, and the two upper layers were relaxed and two lower layers were fixed. A 
$p(3 \times 3)$ supercell with nine active sites was constructed with $4 \times 4 \times 1$ Monkhorst-Pack $k$-point mesh sampling for Brillouin-zone integration ${ }^{51}$, while a $p(2 \times 2)$ supercell using the same $k$-point sampling was used to simplify the model of the coverage-dependent relations. A $\sim 12 \AA$ vacuum layer was placed above the surfaces for both adsorptions and transition states. To minimize the interaction of the neighboring gaseous molecules, the free $\mathrm{O}_{2}$ molecule and NO molecule were placed in a $(10 \times 10 \times 10) \AA^{3}$ cubic box to obtain the total energies. The constrained minimization technique ${ }^{52-54}$ and the quasi-Newton algorithm ${ }^{55}$ were used to find and optimize the transition states. The opitimised structures were reached when the forces on the relaxed atoms were less than $0.01 \mathrm{eV} / \AA$ for adsorption states and $0.05 \mathrm{eV} / \AA$ for the transition states.

All the energies used in this work are free energies. The total energies were corrected to the free energy by considering the thermodynamic corrections of zero-point-energy (ZPE), thermal energy (U) and entropy (S) derived from vibrational partition function. All the transition states were checked by the vibrational frequency analysis. The thermodynamic corrections of the gaseous species were calculated using the Gaussian 03 with ideal gas approximation (only the correction values were used).

For NO oxidation reaction, three elementary steps (NO adsorption, $\mathrm{O}_{2}$ dissociation and O-NO coupling) were considered in this work $^{9}$ (Table 1).

Table 1 Elementary steps and the rate equations of NO oxidation used in the microkinetics modeling (* represents the free site on the surface).

\begin{tabular}{lll}
\hline No. & Element steps & Rate equations \\
\hline 1. & $\mathrm{NO}(\mathrm{g})+* \leftrightarrow \mathrm{NO}^{*}$ & $r_{1}=k_{1} P_{N O} \theta_{*}-k_{-1} \theta_{N O}$
\end{tabular}




$$
\begin{aligned}
& \text { 2. } \mathrm{O}_{2}(\mathrm{~g})+2^{*} \leftrightarrow 2 \mathrm{O}^{*} \quad r_{2}=k_{2} P_{O_{2}} \theta_{*}{ }^{2}-k_{-2} \theta_{O}{ }^{2} \\
& \text { 3. } \mathrm{NO}^{*}+\mathrm{O}^{*} \leftrightarrow \mathrm{NO}_{2}(\mathrm{~g})+2^{*} \quad r_{3}=k_{3} \theta_{\mathrm{NO}} \theta_{O}-k_{-3} P_{\mathrm{NO}_{2}} \theta_{*}{ }^{2}
\end{aligned}
$$

As for the coverage effect, both self and cross interactions of adsorbates were considered in the NO oxidation, in which the main adsorbates are $\mathrm{O}$ and NO. The energy from the most stable structure for each coverage was chosen. There are four different self and cross interactions for adsorption states: $\mathrm{O} / \mathrm{O}_{\mathrm{env}}, \mathrm{O} * \mathrm{NO} \mathrm{O}_{\mathrm{env}}$, $\mathrm{NO} * / \mathrm{NO}_{\text {env }}$ and $\mathrm{NO} * / \mathrm{O}_{\text {env }}$, where $\mathrm{O} *$ and $\mathrm{NO} *$ represent the objective adsorbates and $\mathrm{O}_{\text {env }}$ and $\mathrm{NO}_{\text {env }}$ refer to the species in the environment. Moreover, our rigorous coverage-dependent model also includes the interactions between the transition states and the adsorbates $\left(\mathrm{O}-\mathrm{O} * / \mathrm{O}_{\text {env }}, \mathrm{O}-\mathrm{O} * / \mathrm{NO}_{\text {env }}, \mathrm{O}-\mathrm{NO} * / \mathrm{O}_{\text {env }}\right.$ and $\mathrm{O}-\mathrm{NO} * / \mathrm{NO}_{\text {env }}$, where $\mathrm{O}-\mathrm{O}^{*}$ and $\mathrm{O}-\mathrm{NO}^{*}$ represent the transition states of $\mathrm{O}_{2}$ dissociation and $\mathrm{O}-\mathrm{NO}$ coupling, respectively).

In this work, we introduced a two-line model to obtain the relationship between the differential adsorption energies and the coverages to describe the adsorbates-adsorbates interactions. The maximum total coverage was assumed to 1 ML. For the $p(3 \times 3) \operatorname{Pt}(111)$ surface with one active site being occupied, the coverage of this adsorption state was $0.11 \mathrm{ML}$, and it is $0.25 \mathrm{ML}$ for the $p(2 \times 2) \mathrm{Pt}(111)$ surface in the same situation. The differential adsorption energy is defined as the adsorption energy changed from the coverage of $\mathrm{N}$ sites being occupied $\left(\theta_{\mathrm{N}}\right)$ to the coverage of $\mathrm{N}+1$ sites being occupied $\left(\theta_{\mathrm{N}+1}\right)$. Due to the linear nature of the energy-coverage relation, the corresponding coverage for the differential adsorption energy is the 
average value of these two coverages $\left(1 / 2\left(\theta_{\mathrm{N}}+\theta_{\mathrm{N}+1}\right)\right)^{36}$. Therefore, the differential energy $\left(E_{a d}^{\text {diff }}\right)$ can be written as:

$$
\begin{aligned}
& E_{a d}^{d i f f}\left(\frac{\theta_{N}+\theta_{N+1}}{2}\right)=E_{a d}\left(\theta_{N+1}\right)-E_{a d}\left(\theta_{N}\right) \\
& E_{a d}^{d i f f}(\theta)=k_{i / j} \times \theta+b_{i / j}
\end{aligned}
$$

where $\theta, \theta_{N}, i, j, k$ and $b$ represent the total coverage, the coverage of $\mathrm{N}$ adsorbates, the objective adsorbate, the environment adsorbates, and the slope and intercept of the two-line model, respectively. On the effect of coverage dependence, the adsorption energy of the species $i$ (e.g. O*) consisted of the contributions of the differential adsorption energy calculated from the self- and cross-interactions of the species $i$ (e.g. $\mathrm{O} * / \mathrm{O}_{\text {env }}$ and $\mathrm{O} * / \mathrm{NO}_{\text {env }}$ ) which is shown below:

$$
E_{a d(i)}=\sum_{j}\left\{\left[E_{a d}^{d i f f}(\theta)-b_{i / j}^{l o w}\right] \times \frac{\theta_{j}}{\theta}+b_{i / j}^{l o w}\right\}
$$

where $\theta, \theta_{j}$ and $E_{a d(i)}$ are the total coverage of all the species, the coverage of environment species $j$ and the coverage-dependent adsorption energy of adsorbate $i$, respectively. The corrected transition state energy is defined as the total energy of the transition state on the surface covered with the adsorbates minus the total energy of the corresponding adsorption state with the same coverage of adsorbates.

The turn-over frequency (TOF) was calculated by the full microkinetics modeling ${ }^{28,}$ 56, which was performed under experimental conditions of $600 \mathrm{~K}$ with the partial pressures of $\mathrm{O}_{2}$, NO and $\mathrm{NO}_{2}$ being 0.10 bar, $3 \times 10^{-4}$ bar and $1.7 \times 10^{-4}$ bar, respectively ${ }^{9,} 34$ for the purpose of comparison. The microkinetics modeling was 
performed using the code developed by our group ${ }^{57}$. A new approach to obtain the coverage-dependent TOF is illustrated in the Supporting Information.

\section{Results and discussions}

\section{Coverage-dependent adsorption energies}

To investigate the effect of coverage-dependent NO oxidation on $\operatorname{Pt}(111)$, we systematically study the self and cross adsorbate-adsorbate interactions of the main adsorption species (O atom and NO molecule). Taking oxygen as an example, there are nine typical structures of $\mathrm{O}$ atoms adsorbed on the $p(3 \times 3) \operatorname{Pt}(111)$ surface (Figure 1). The adsorption energy of $\mathrm{O}$ with a coverage of $0.11 \mathrm{ML}$ was used in the coverage independence model. When increasing the amount of $\mathrm{O}$ atoms on the surface, the adsorption energy of $\mathrm{O}$ becomes weaker. This can be easily understood considering the bonding competition effect and the Pauli repulsion effect ${ }^{58-60}$ : When an adsorbate bonds with the surface, the surface becomes inert for further bonding with the second adsorbate, leading to an decrease of adsorption energy. The more adsorbates the surface possesses, the weaker the adsorption energy. The differential adsorption energies of oxygen on the oxygen-covered surface are shown in Figure 2a. It shows that interestingly, unlike results reported previously ${ }^{36,38}$, the differential adsorption energies at the low coverages are not constant. Instead, they change by $0.40 \mathrm{eV}$ going from $0.056 \mathrm{ML}$ to $0.278 \mathrm{ML}$, which is quite significant. The differential adsorption energy changes slightly below the total coverage of $0.278 \mathrm{ML}$, while it decreases dramatically when the coverage is increased beyond the total coverage of $0.278 \mathrm{ML}$. 
Herein, we introduce a two-line model to describe the relationship between the differential adsorption energy and the coverage.
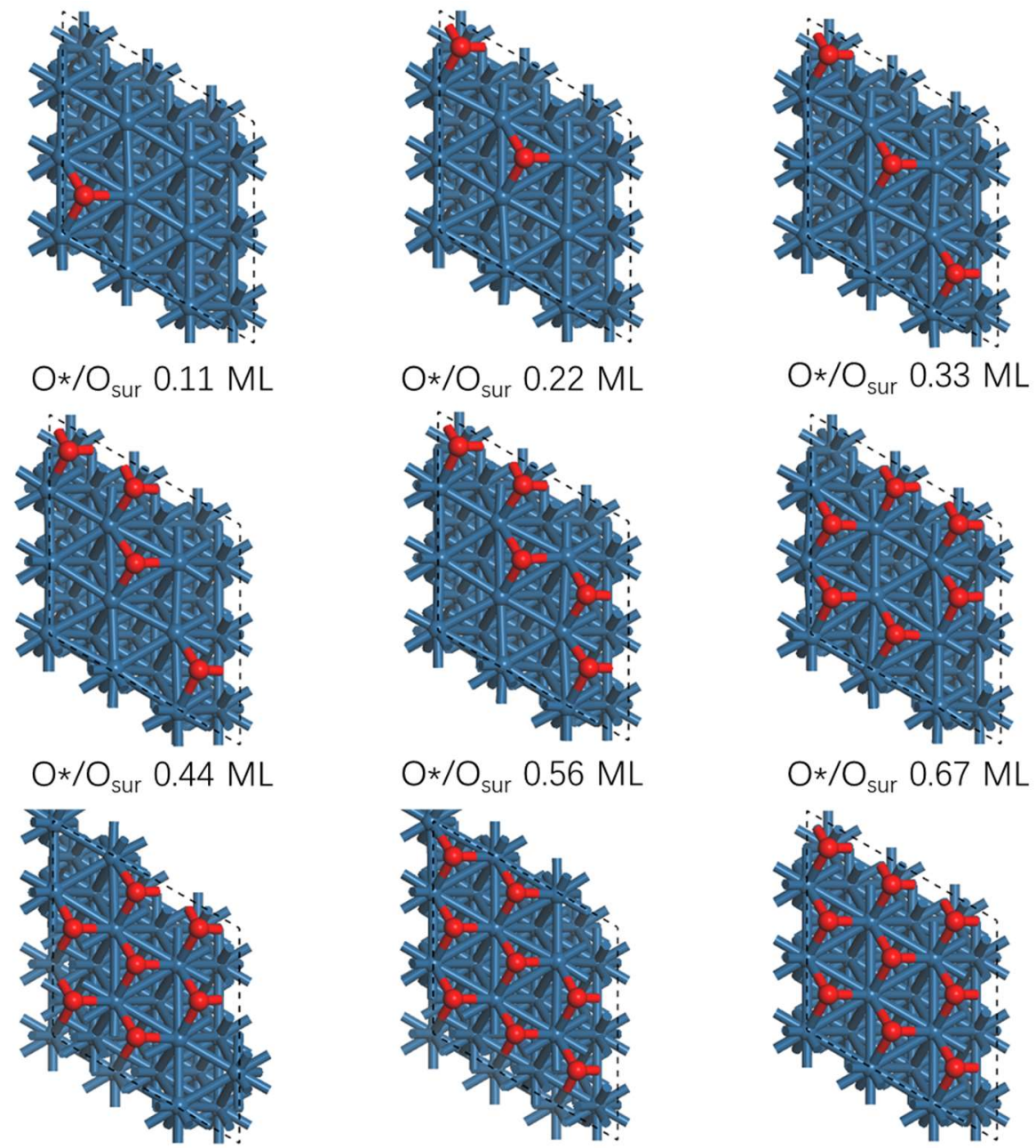

$$
\mathrm{O} * / \mathrm{O}_{\text {sur }} 0.78 \mathrm{ML}
$$

$\mathrm{O} * / \mathrm{O}_{\text {sur }} 0.89 \mathrm{ML}$

$\mathrm{O} * / \mathrm{O}_{\text {sur }} 1.00 \mathrm{ML}$

Figure 1 The structures of $\mathrm{O}^{*} / \mathrm{O}_{\text {env }}$ at the coverages from $0.11 \mathrm{ML}$ to $1.00 \mathrm{ML}$. The red and dark blue atoms represent the oxygen and $\mathrm{Pt}$, respectively.

By calculating the full microkinetics of the NO oxidation reaction with a coverage independence model, the coverages of $\mathrm{O}$ and $\mathrm{NO}$ at the steady state can be obtained, which are $0.38 \mathrm{ML}$ and $0.60 \mathrm{ML}$, respectively. It indicates that both $\mathrm{O}$ and NO adsorb on the surface with a fair amount of coverages, which means that the $\mathrm{O}$ atom is surrounded not only by covered oxygen, but also by NO (Figure S1). Namely, there 
are the cross-interactions. Similarly, both the self- and cross-interactions for NO were considered (see structures in Figure S2 and S3). In this work, the cross-interaction was explicitly calculated at each coverage as well as the self-interaction (Figure 2). Evidently, a total coverage of $0.278 \mathrm{ML}$ is found to be the turning point between the low and high coverages for both self and cross adsorbate-adsorbate interactions. The slopes of each self- and cross-interactions of the adsorption states are shown in Table

2.

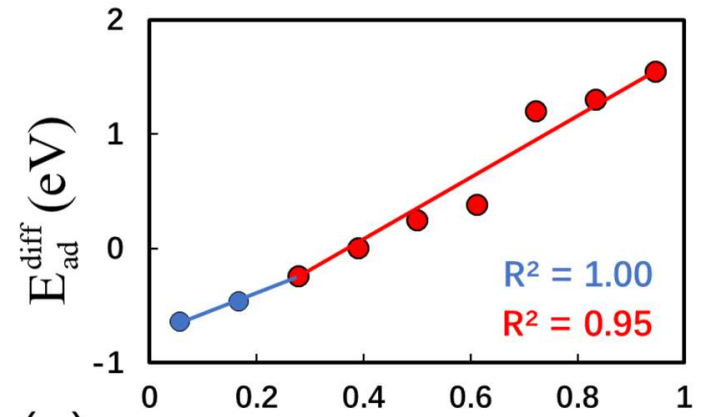

(a)
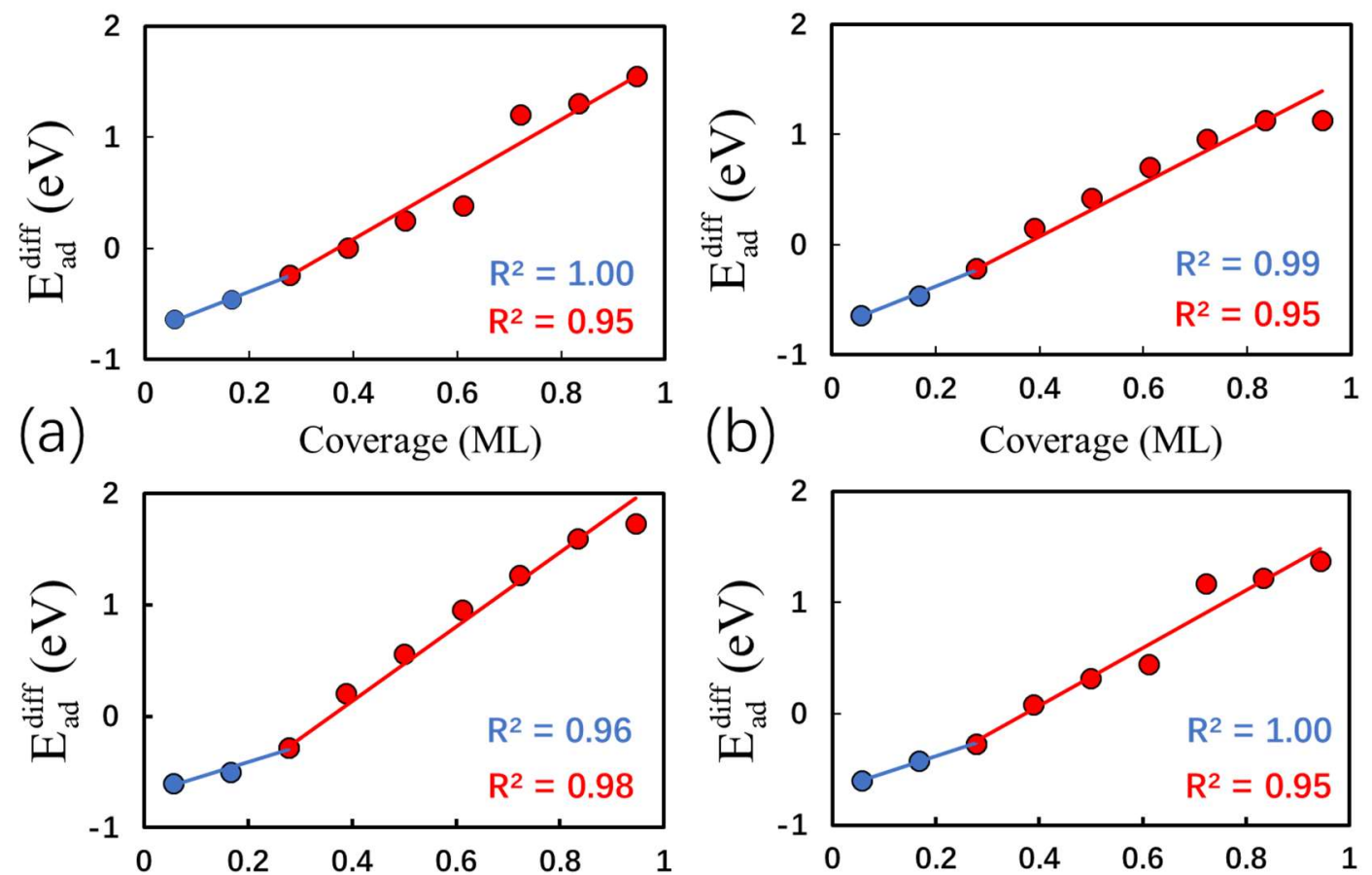

(b)

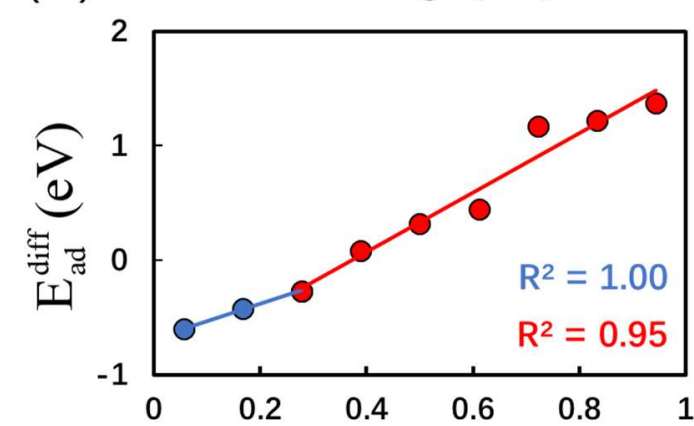

(c)

Coverage (ML)

(d)

Coverage (ML)

Figure 2 Relationships between differential adsorption energies and coverages of (a)

$\mathrm{O} * / \mathrm{O}_{\text {env }}$, (b) $\mathrm{O} * \mathrm{NO}_{\text {env }}$, (c) $\mathrm{NO} * / \mathrm{NO}_{\text {env }}$ and (d) $\mathrm{NO} * / \mathrm{O}_{\text {env }}$ on the $p(3 \times 3)-\mathrm{Pt}(111)$. It can be seen that they can be described by two linear lines, and it is named as a two-line model. 
Table 2 Slopes of the self- and cross-interaction curves between adsorbates and adsorbates in Figure 2 and Figure 6. Slopes of interaction curves between adsorbates and transition states of $\mathrm{O}_{2}$ dissociation and $\mathrm{O}-\mathrm{NO}^{*}$ coupling in Figure 3 and Figure $\mathrm{S} 8$ are also listed. The surfaces are $p(3 \times 3)-\operatorname{Pt}(111)$ and $p(2 \times 2)-\operatorname{Pt}(111)$.

\begin{tabular}{cccc}
\hline \multirow{2}{*}{$\begin{array}{c}\text { Self- and cross- } \\
\text { interaction }\end{array}$} & \multicolumn{2}{c}{ slope $p(3 \times 3)$} & slope $p(2 \times 2)$ \\
\cline { 2 - 3 } & low coverage & high coverage & \\
\hline $\mathrm{O}^{*} / \mathrm{O}_{\text {env }}$ & 1.801 & 2.867 & 2.837 \\
$\mathrm{O}^{*} / \mathrm{NO}_{\mathrm{env}}$ & 1.914 & 2.102 & 2.502 \\
$\mathrm{NO} / \mathrm{NO}_{\text {env }}$ & 1.461 & 3.053 & 3.274 \\
$\mathrm{NO} / \mathrm{O}_{\text {env }}$ & 1.507 & 2.590 & 2.634 \\
$\mathrm{O}-\mathrm{O} * / \mathrm{O}_{\text {env }}$ & 1.753 & 6.104 & 2.895 \\
$\mathrm{O}-\mathrm{O} * \mathrm{NO}_{\mathrm{env}}$ & 1.751 & 4.935 & 2.199 \\
$\mathrm{O}-\mathrm{NO} * / \mathrm{NO}_{\text {env }}$ & 2.125 & 4.492 & 2.977 \\
$\mathrm{O}-\mathrm{NO} / \mathrm{O}_{\text {env }}$ & 1.856 & 4.878 & 3.006 \\
\hline
\end{tabular}

\section{Rigorous coverage-dependent model}

It is obvious that the reaction barriers are essential in the reaction kinetics. After studying the total energies of the transition state at different coverages, we noticed that the surrounding adsorbates would also significantly affect the transition state energies. Thus, the corrections should also be applied to the transition state energies with coverage effects. To unravel the relationship between the transition state and the adsorbates, the TS-adsorbate interactions were systemically studied. Unlike the adsorption state, the transition states of both $\mathrm{O}_{2}$ dissociation and $\mathrm{O}-\mathrm{NO}$ coupling occupy more sites on the surface, due to two reactants involved. Some structures of 
the TS-adsorbate interactions are illustrated in Figure S4. The bond distances of O-O and O-NO change from $1.987 \AA$ to $2.145 \AA$ and $1.761 \AA$ to $1.869 \AA$, respectively, corresponding to the coverage range of $0.22 \mathrm{ML}$ to $0.56 \mathrm{ML}$. It indicates that the transition states are closer to the adsorption state (willing to dissociate) with the coverage increase. However, the bond distances of O-O and O-NO decrease to 1.952 $\AA$ and $1.681 \AA$, respectively, at the coverage of $0.89 \mathrm{ML}$, on account of the crowded surfaces causing the transition states to be closer to the gaseous species (willing to associate). By rigorously investigating the free energies of the transition states covered with different coverages of $\mathrm{O}$ and $\mathrm{NO}$, the corrected transition state energies exhibit a similar trend as the differential adsorption energies: With the total coverage increase, the differential transition state energy becomes weaker.

The turning point of the corrected transition state energy vs the total coverage is found to be $0.5 \mathrm{ML}$. The TS-adsorbate interactions of $\mathrm{O}_{2}$ dissociation $(\mathrm{O}-\mathrm{O})$ and O-NO coupling with the covered $\mathrm{O}$ and $\mathrm{NO}$ are illustrated in Figure 3, while the slopes of TS-adsorbate interactions are shown in Table 2. The slopes of $\mathrm{O}-\mathrm{O} * / \mathrm{O}_{\text {env }}$ (1.753) and $\mathrm{O}-\mathrm{O} * / \mathrm{NO}_{\text {env }}(1.751)$ are almost the same in the low coverage region, indicating that the environments of the covered $\mathrm{O}$ and $\mathrm{NO}$ contribute to the same corrections to the transition state of $\mathrm{O}_{2}$ dissociation at the low coverages. However, with the coverage increase beyond $0.5 \mathrm{ML}$, the covered $\mathrm{O}$ would affect the TS energy more than the covered NO, due to the stronger adsorption energy of $\mathrm{O}$ than $\mathrm{NO}$, which leads to the slope of $\mathrm{O}-\mathrm{O} * / \mathrm{O}_{\text {env }}$ (6.104) apparently higher than that of 
$\mathrm{O}-\mathrm{O} * / \mathrm{NO}_{\text {env }}(4.935)$ in the high coverage region. The same trend is identified in the O-NO coupling at high coverages.

Interestingly, as for adsorbate-adsorbate interactions in the low coverage region, $\mathrm{O} * / \mathrm{O}_{\text {env }}(1.801)$ and $\mathrm{O} / \mathrm{NO}_{\text {env }}(1.914)$ have similar slopes, and the slopes of $\mathrm{NO} * / \mathrm{NO}_{\text {env }}(1.461)$ and $\mathrm{NO} * / \mathrm{O}_{\text {env }}(1.507)$ are also comparable, which is consistent with the TS-adsorbate interactions. Taking both adsorbate-adsorbate interactions and TS-adsorbate interactions into consideration, it is not difficult to find that the slopes at the low coverages were determined by the objective adsorbates $\left(\mathrm{O}^{*}\right.$ and $\left.\mathrm{NO}^{*}\right)$ or the transition state structures $\left(\mathrm{O}-\mathrm{O}^{*}\right.$ and $\left.\mathrm{O}-\mathrm{NO}^{*}\right)$, while they are dominated by the covered environment $\left(\mathrm{O}_{\text {env }}\right.$ and $\left.\mathrm{NO}_{\text {env }}\right)$ in the high coverage region. Herein, we name the combination of the adsorbate-adsorbate interaction model and the TS-adsorbate interaction model as a rigorous coverage-dependent model.

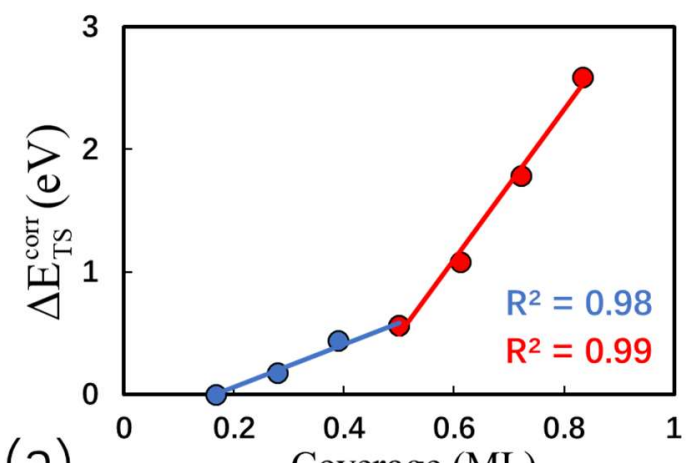

(a)
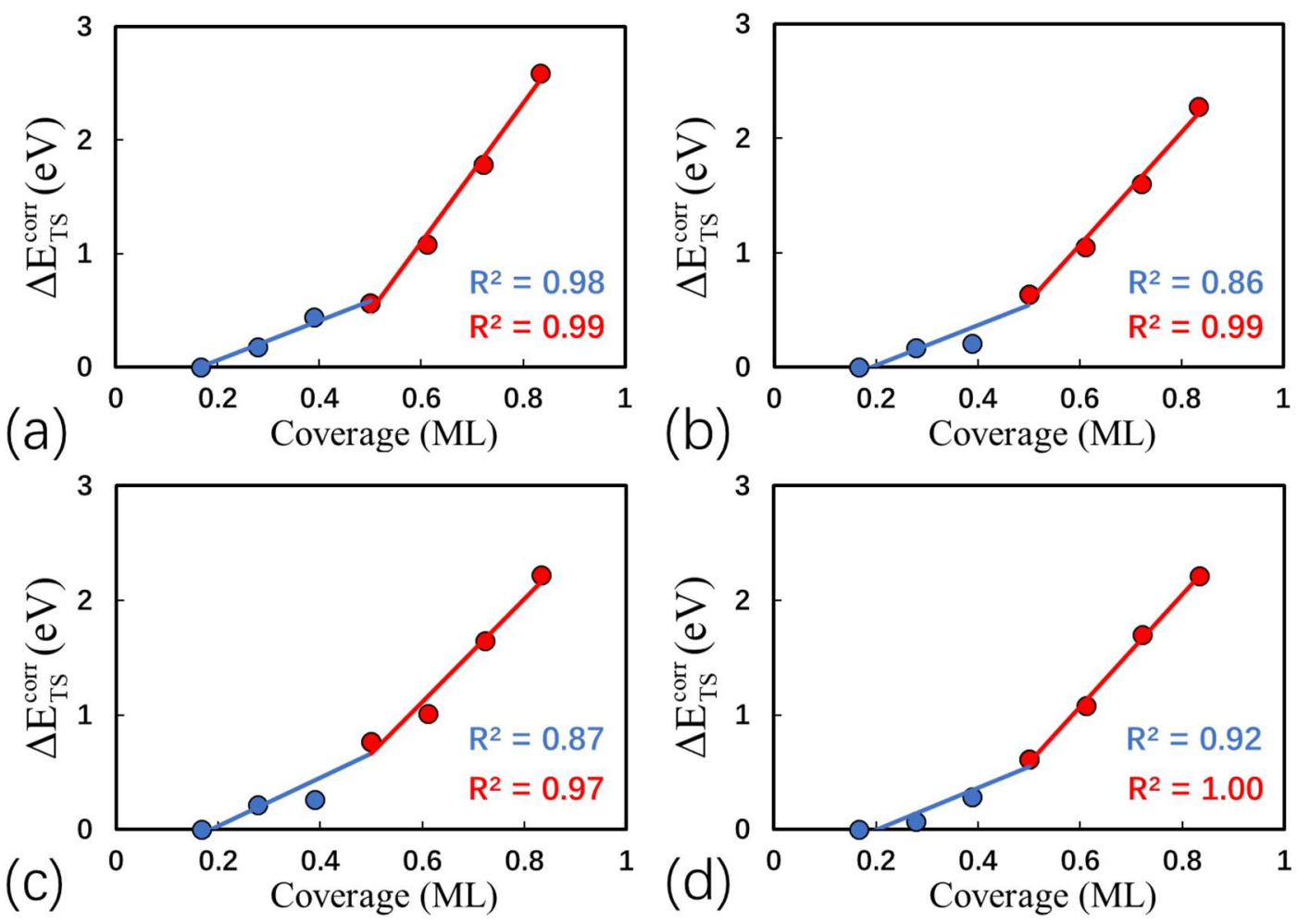
Figure 3 Relationships between the corrected transition state energies and coverages of (a) O-O*/Oenv, (b) O-O*/NOenv, (c) O-NO*/NOenv and (d) O-NO*/Oenv on the $p(3 \times 3)-\operatorname{Pt}(111)$.

\section{Full microkinetics analysis with different models}

Having obtained the self and cross adsorbate-adsorbate interactions of $\mathrm{O}$ and $\mathrm{NO}$ and also the TS-adsorbate interactions of $\mathrm{O}_{2}$ dissociation and $\mathrm{O}-\mathrm{NO}$ coupling, they can be applied to calculate the TOF with the coverage effect explicitly. The TOF with the rigorous coverage-dependent model was $0.22 \mathrm{~s}^{-1}$ (Figure 4 column E), which was almost the same as the experiment value $\left(\sim 0.2 \mathrm{~s}^{-1}\right)^{31,34}$ and also similar to the TOF reported by Schneider and co-workers in their coverage-dependent kinetic studies ${ }^{37,44}$. Comparing with the coverage independent model (Figure 4 column B), the rigorous coverage-dependent model plays an important role in bridging the theoretical calculation and the experiment.

In the literature, some empirical and approximation methods were suggested to correct the transition state energy with the coverage effect. In this work, we calculated the TOF using these approaches in conjunction with the coverage-dependent adsorption energies carried out by our adsorbate-adsorbate interaction model. The most convenient method is to use the BEP relations, which can be used to estimate the reaction barriers as a function of adsorption energies. Having obtained the adsorbate-adsorbate interactions, the adsorption energy at a specific coverage can be easily acquired, which can be used to predict the transition state energy. By using the self- and cross-interactions to correct the adsorption energies and the BEP relations 
(Figure S6) to calculate the transition state energies, the TOF was obtained at the steady state (Figure 4 column A). However, the TOF $\left(335 \mathrm{~s}^{-1}\right)$ calculated by this method was apparently higher than the experiment result $\left(\sim 0.2 \mathrm{~s}^{-1}\right)$.

In additional to the BEP relation, we used another method ${ }^{45}$ to estimate the activity barriers with the coverage effect: The weighted contributions from the variations in adsorption energies of the initial state and final state were applied to the transition state energy. It is named as the $\mathrm{X} / \mathrm{Y}$ model, in which the contribution ratios from the initial state and final state to each transition state are $\mathrm{X}$ and $\mathrm{Y}$, respectively. Four different approximation models were tested in this work (for detailed results see the Supporting Information). Comparing with the experimental TOF $\left(\sim 0.2 \mathrm{~s}^{-1}\right)^{31,34}$, the 0/1 model for $\mathrm{O}_{2}$ dissociation and 1/0 model for O-NO coupling (Figure 4 column $\mathrm{C}$ ) in these four approximation models was the closest, with the TOF to be $1.54 \mathrm{~s}^{-1}$. In this reaction system, the transition state structure of $\mathrm{O}_{2}$ dissociation is closer to the $\mathrm{O}$ adsorption state, which results in the correction of the transition state energy to be fully contributed by the change of the O coverage-dependent adsorption energy. In contrast, the TS energy change of O-NO coupling is only corrected by the initial state, due to the early transition-state-like structure. Comparing with the coverages of rigorous coverage-dependent model ( $0.38 \mathrm{ML}$ for $\mathrm{O}$ and $0.11 \mathrm{ML}$ for NO), the best approximation model has the comparable $\mathrm{O}$ coverage $(0.42 \mathrm{ML})$ and NO coverage (0.08 ML). Interestingly, although the exact coverages of $\mathrm{O}$ and NO calculated by these models are different, the total coverages are all around $0.50 \mathrm{ML}$, unlike the total 
coverage of the coverage-independent model, which is $0.98 \mathrm{ML}$. Once again, it indicates the importance of the coverage in microkinetics calculation.

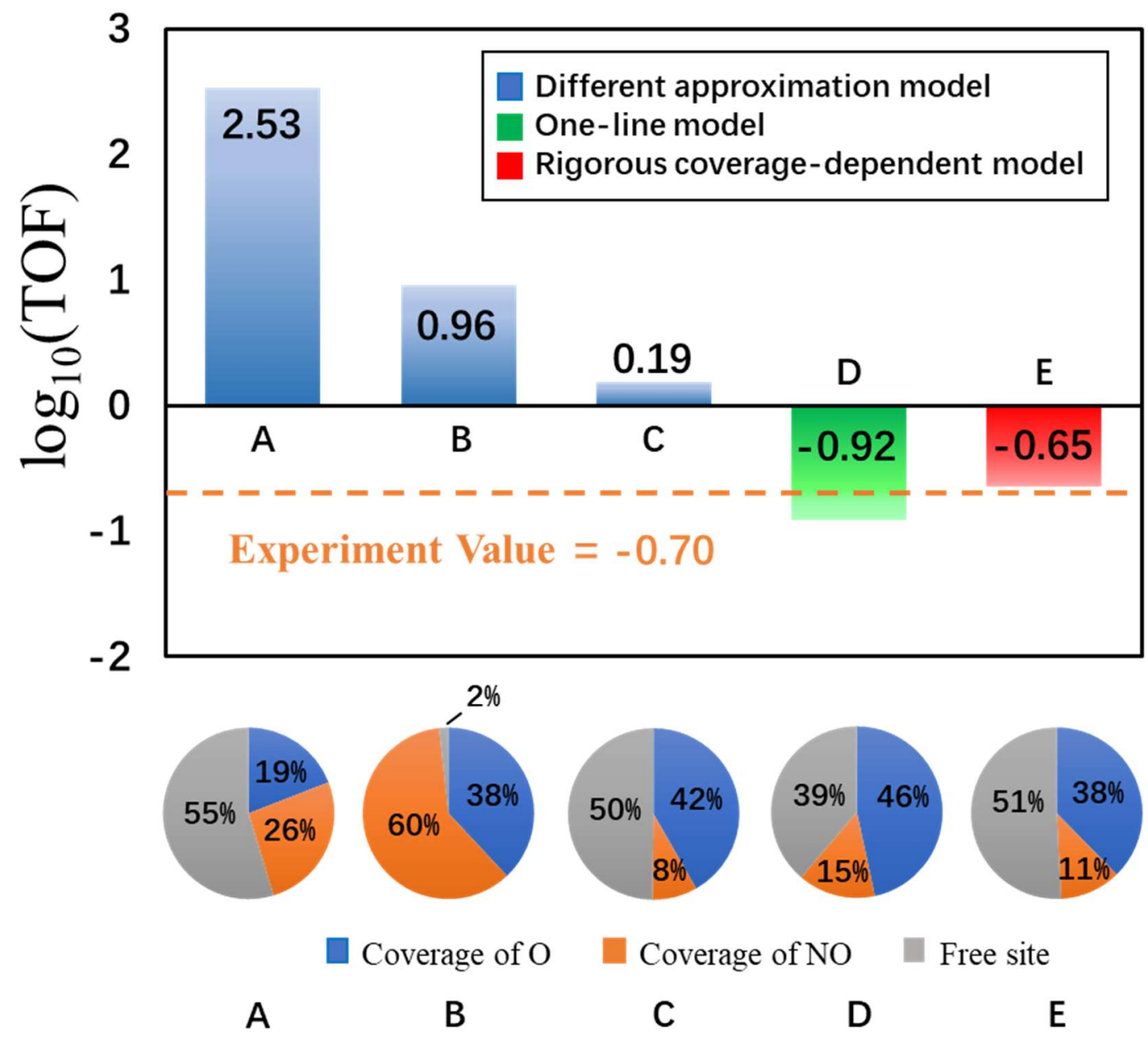

Figure 4 TOF values and surface coverages of NO oxidation calculated by the methods of (A) BEP relations, (B) coverage independent model, (C) 0/1 model for $\mathrm{O}_{2}$ dissociation and 1/0 model for O-NO coupling, (D) one-line model, (E) rigorous coverage-dependent model. The orange dash line represents the experiment value. The coverages of $\mathrm{O}^{*}, \mathrm{NO}^{*}$ and free site are in blue, orange and grey, respectively.

Taking the result from the rigorous coverage-dependent model as a benchmark, the energy profiles of all different models are illustrated in Figure 5 (for detailed data see the Supporting Information). The rate-determining step of this reaction with the 
coverage-independent model is $\mathrm{O}-\mathrm{NO}$ coupling, the barrier of which is $0.4 \mathrm{eV}$ higher than that of $\mathrm{O}_{2}$ dissociation. This leads to more NO adsorbed on the surface, which is 0.60 ML coverage. However, the results calculated using the rigorous coverage-dependent model show that $\mathrm{O}_{2}$ dissociation and $\mathrm{O}-\mathrm{NO}$ coupling possess the same energy barriers, indicating that the rate-determining step of the reaction is changed by including the coverage effect. The increased $\mathrm{O}_{2}$ dissociation barrier results in a low TOF comparing with the coverage-independent model. Liu and co-workers ${ }^{61}$ reported the same conclusion that the rate-determining step would be changed with the coverage increased, which would even affect the selectivity of the reaction.

Interestingly, the reaction barriers of both the $\mathrm{O}_{2}$ dissociation and the O-NO coupling predicted by the BEP relations are also the same but $0.4 \mathrm{eV}$ lower than that from the rigorous coverage-dependent model, which lead to a higher TOF. This is caused by the under-estimation of the energy barriers from the BEP relations. As for the best approximation model (the $0 / 1$ model for $\mathrm{O}_{2}$ dissociation and 1/0 model for O-NO coupling), the reaction barriers of both the $\mathrm{O}_{2}$ dissociation and the O-NO coupling are the same as well, which are $0.1 \mathrm{eV}$ lower than those of the rigorous coverage-dependent model. Moreover, the coverages of $\mathrm{O}$ and NO from the best approximation model is similar with the rigorous coverage-dependent model. To some extent, the best approximation method can reach the accuracy of the rigorous coverage-dependent model. However, whether the best approximation model (the 0/1 model for $\mathrm{O}_{2}$ dissociation and $1 / 0$ model for $\mathrm{O}-\mathrm{NO}$ coupling) is general remain to be 
studied, while the approach of the rigorous coverage-dependent model can be widely used in all the systems.

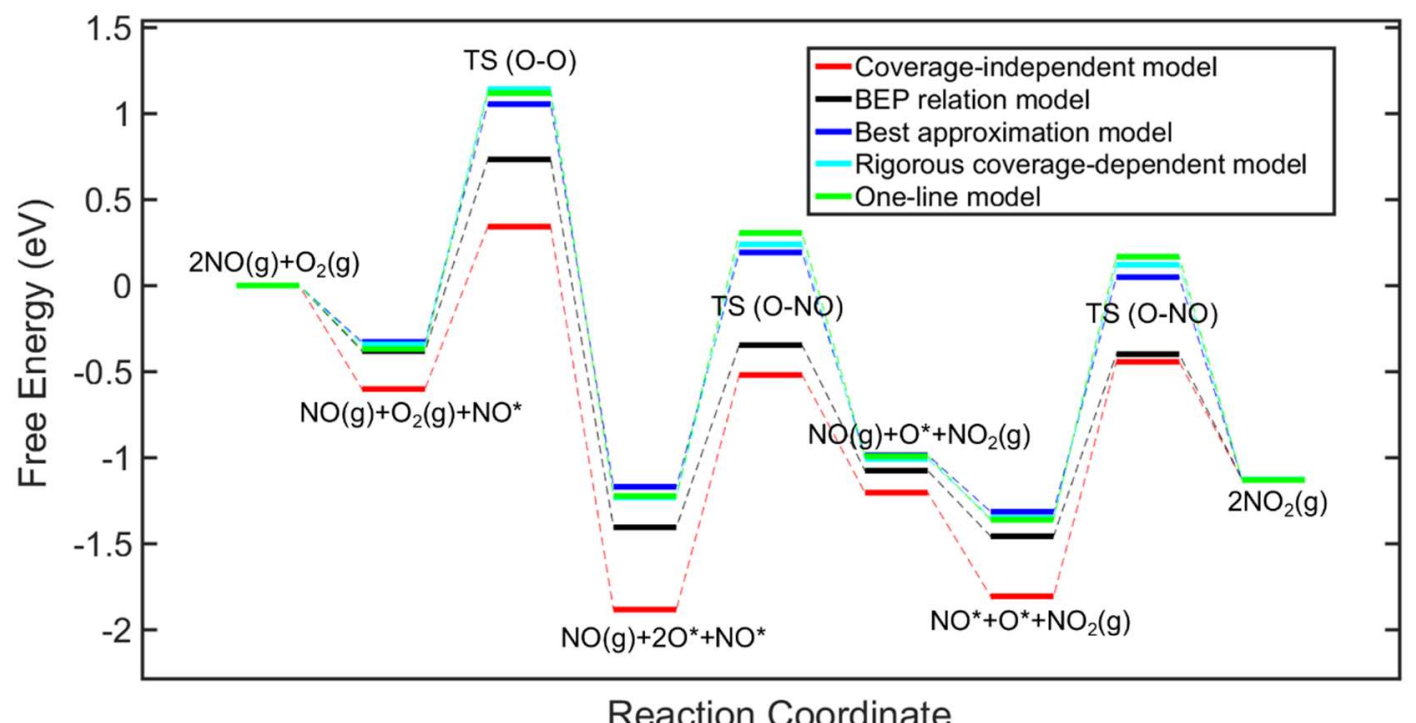

Figure 5 Analysis of different models in kinetic calculations with respect to the results of the rigorous coverage-dependent model, in which the free energy profiles are compared. The free energy profiles of NO oxidation with coverage-independent model (red), the BEP relation model (black), the best approximation model (blue), the rigorous coverage-dependent model (light blue, is considered to be a benchmark) and the one-line model (green).

\section{The simplified one-line model}

Despite our rigorous coverage-dependent model can give rise to accurate kinetic results, extensive calculations were needed to obtain the coverage-dependent energies. In particular, all the interaction energies were obtained from the $\mathrm{p}(3 \times 3)$ unit cell, which was quite time-consuming. Can this process be simplified? It is noticed that the total coverage of $\mathrm{O}$ and $\mathrm{NO}$ is over $0.278 \mathrm{ML}$ at the steady state for this reaction. This 
means that the self and cross-interactions of the reasonably high coverage region were mostly used and the low coverage region might be ignored. The coverage from the $p(2 \times 2)$ unit cell gives rise to $0.25 \mathrm{ML}$, which can satisfy this condition. Thus, the $p(2 \times 2)$ unit cell of $\operatorname{Pt}(111)$ was used to simplify the self and cross adsorbate-adsorbate interactions (Figure S5). The differential adsorption energies as a function of coverages are illustrated in Figure 6, while the slopes of these self and cross interactions are listed in Table 2. These differential adsorption energies of each adsorbate vs the coverages were integrated as a one line for the correction purpose, the so-called one-line model. Interestingly, the slopes of adsorbate-adsorbate interactions in the one-line model are similar to those of the two-line model in the high coverage region.

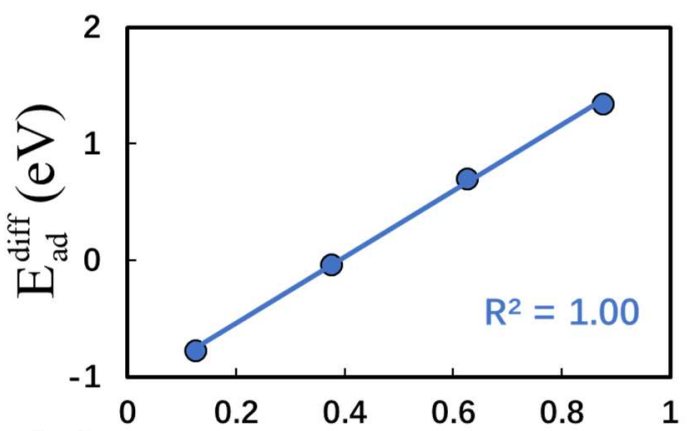

(a) Coverage (ML)

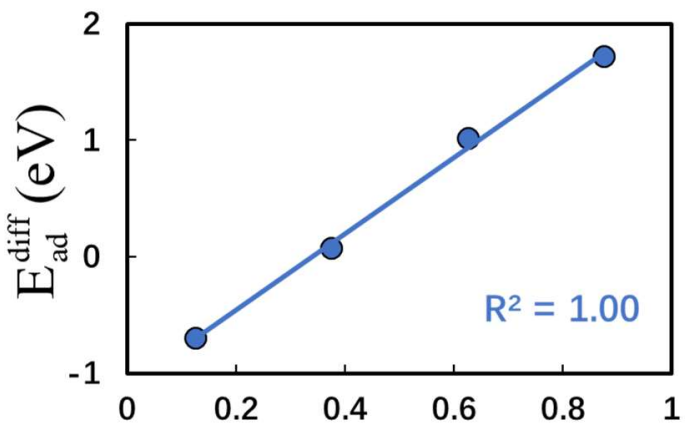

(C) Coverage (ML)

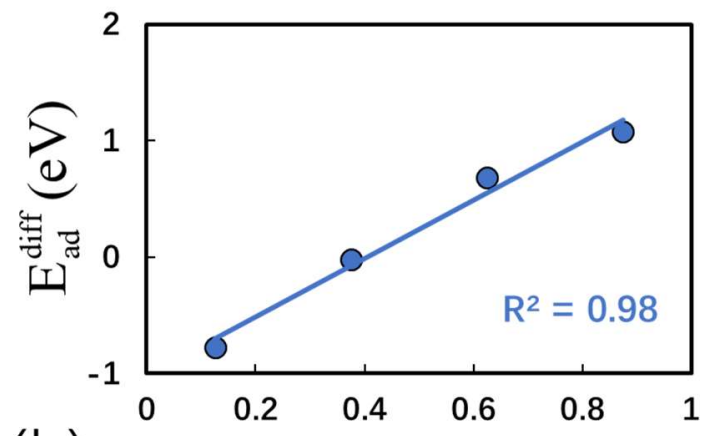

(b)

Coverage (ML)

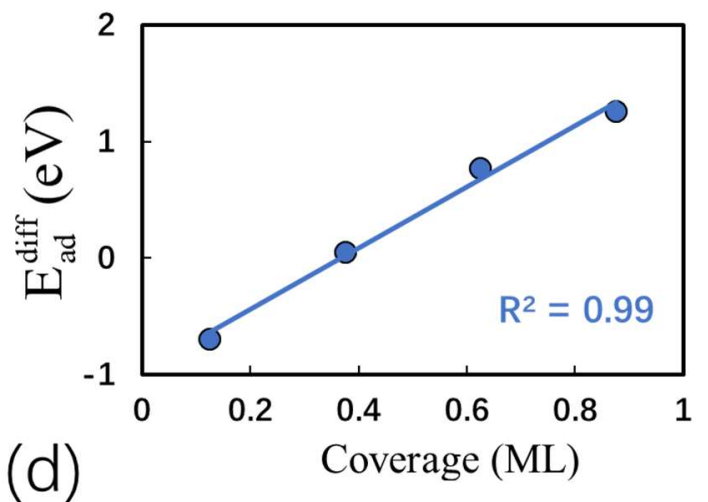


Figure 6 Relationships between differential adsorption energies and coverages of (a) $\mathrm{O} * / \mathrm{O}_{\text {env }}$, (b) $\mathrm{O} * / \mathrm{NO}_{\text {env }}$, (c) $\mathrm{NO} * / \mathrm{NO}_{\text {env }}$ and (d) $\mathrm{NO} * / \mathrm{O}_{\text {env }}$ on the $p(2 \times 2)-\mathrm{Pt}(111)$. Linear curves can be seen and the approach to calculate the coverage effect is named as the one-line model.

The BEP relation model and the TS-adsorbate interaction model (Table 2) were also chosen to test the feasibility of the one-line model, and the TOF values with the coverage effect were performed, giving rise to $463 \mathrm{~s}^{-1}$ and $0.12 \mathrm{~s}^{-1}$ from these two models, respectively. The detailed data of one-line BEP model were compared with those of the two-line model with the BEP relation method (Table 3), which shows that adsorption energies and activity barriers are almost the same, indicating no major difference between one-line model and two-line model by BEP relations. Also, the one-line model with TS-adsorbate interactions gives rise to similar adsorption energies and reaction barriers to those of the rigorous coverage-dependent model, which are highly consistent with the TOF from experimental results. It is clear that the one-line model has a good performance for kinetic calculations of NO oxidation.

Table 3 The adsorption energies $(\mathrm{eV})$, reaction barriers $(\mathrm{eV})$, coverages $(\mathrm{ML})$ of $\mathrm{O}$ and NO and the TOFs $\left(\mathrm{s}^{-1}\right)$ of different coverage-dependent models.

\begin{tabular}{cccccccc}
\hline Coverage model & $\mathrm{E}_{\mathrm{ad}} \mathrm{O}$ & $\mathrm{E}_{\mathrm{ad}} \mathrm{NO} \mathrm{E}_{\mathrm{a}}(\mathrm{O}-\mathrm{O})$ & $\mathrm{E}_{\mathrm{a}}(\mathrm{O}-\mathrm{NO})$ & $\theta_{\mathrm{O}}$ & $\theta_{\mathrm{NO}}$ & $\mathrm{TOF}$ \\
\hline Two-line BEP model & -0.51 & -0.38 & 1.11 & 1.06 & 0.19 & 0.26 & 335 \\
One-line BEP model & -0.55 & -0.39 & 1.07 & 1.08 & 0.34 & 0.24 & 463 \\
$\begin{array}{c}\text { Rigorous } \\
\text { coverage-dependent } \\
\text { model }\end{array}$ & -0.44 & -0.34 & 1.48 & 1.47 & 0.38 & 0.11 & 0.22 \\
& & & & & & &
\end{tabular}


$\begin{array}{llllllll}\text { One-line model } & -0.43 & -0.37 & 1.49 & 1.53 & 0.46 & 0.15 & 0.12\end{array}$

\section{Conclusion}

In this work, a coverage-dependent microkinetics modeling for NO oxidation on Pt(111) using DFT energetics was carried out, from which the calculated TOF of the NO oxidation agrees well with experimental results. To achieve this, both the self and cross adsorbate-adsorbate interactions were rigorously included. Furthermore, the interaction between the adsorbates and the transition states is also needed in order to obtain the reliable results. It was found that both the adsorbate-adsorbate interactions and the coverage effect on the transition states can be described by a two-line model. Some approximations in the literature were tested against the experimental result and the rigorous coverage-dependent microkinetics modeling. It was found that using BEP relations can give rise to an error of two orders of magnitude. A one-line model was used to simplify the two-line model, which is much less time-consuming compared to the two-line model and is capable of giving rise to an accurate TOF value.

\section{ASSOCIATED CONTENT}

\section{Supporting Information}

The Supporting Information is available free of charge on the ACS Publications website at DOI: XXXX.

The coverage-dependent microkinetics calculation approach, the structures of the adsorbate-adsorbate interactions and TS-adsorbate interactions, BEP relations of $\mathrm{O}_{2}$ dissociation and $\mathrm{O}-\mathrm{NO}$ coupling, the results of different approximation TS models (PDF) 


\section{AUTHOR INFORMATION}

\section{Corresponding Authors}

*(P.H.) E-mail: p.hu@qub.ac.uk

\section{ORCID}

P. Hu: 0000-0002-6318-1051

\section{Author Contributions}

P.H. conceived the project. Y.X.D. performed all the calculations. Y.X.D. wrote the first draft of the manuscript, and all the authors contributed to the revision of the manuscript.

\section{Notes}

The authors declare no competing financial interest.

\section{ACKNOWLEDGMENTS}

The authors gratefully acknowledge the UK's national high performance computing service ARCHER and QUB high performance computing center for computing resources. Y.X.D thanks the Queen's University Belfast and China Scholarship Council for the PhD studentship.

\section{References}

1. Huang, Y.; Cao, J.-J.; Kang, F.; You, S.-J.; Chang, C.-W.; Wang, Y.-F. High Selectivity of Visible-Light-Driven La-doped $\mathrm{TiO}_{2}$ Photocatalysts for NO Removal. Aerosol Air Qual. Res. 2017, 17, 2555-2565.

2. Wang, X.; Du, X.; Zhang, L.; Yang, G.; Chen, Y.; Ran, J. Simultaneous Fast Decomposition of $\mathrm{NH}_{4} \mathrm{HSO}_{4}$ and Efficient $\mathrm{NO}_{\mathrm{x}}$ Removal by $\mathrm{NO}_{2}$ Addition: An Option for $\mathrm{NO}_{\mathrm{x}}$ Removal in $\mathrm{H}_{2} \mathrm{O} / \mathrm{SO}_{2}$-Contained Flue Gas at a Low Temperature. Energy Fuels 2018, 32, 6990-6994.

3. Barreau, M.; Tarot, M. L.; Duprez, D.; Courtois, X.; Can, F. Remarkable Enhancement of the Selective Catalytic Reduction of NO at Low Temperature by 
Collaborative Effect of Ethanol and $\mathrm{NH}_{3}$ over Silver Supported Catalyst. Appl. Catal., B 2018, 220, 19-30.

4. Roy, S.; Baiker, A. $\mathrm{NO}_{\mathrm{x}}$ Storage-reduction Catalysis: From Mechanism and Materials Properties to Storage-reduction Performance. Chem. Rev. 2009, 109, 4054-91.

5. Pazmiño, J. H.; Miller, J. T.; Mulla, S. S.; Nicholas Delgass, W.; Ribeiro, F. H. Kinetic Studies of the Stability of $\mathrm{Pt}$ for NO Oxidation: Effect of Sulfur and Long-term Aging. J. Catal. 2011, 282, 13-24.

6. Metkar, P. S.; Balakotaiah, V.; Harold, M. P., Experimental and Kinetic Modeling Study of NO Oxidation: Comparison of $\mathrm{Fe}$ and $\mathrm{Cu}$-zeolite Catalysts. Catal. Today 2012, 184, 115-128.

7. Hong, Z.; Wang, Z.; Li, X. Catalytic Oxidation of Nitric Oxide (NO) over Different Catalysts: an Overview. Catal. Sci. Technol. 2017, 7, 3440-3452.

8. Liu, G.; Gao, P.-X. A Review of $\mathrm{NO}_{\mathrm{x}}$ Storage/Reduction Catalysts: Mechanism, Materials and Degradation Studies. Catal. Sci. Technol. 2011, 1, 552.

9. Wang, H.; Guo, Y.; Lu, G.; Hu, P. An Understanding and Implications of the Coverage of Surface Free Sites in Heterogeneous Catalysis. . J. Chem. Phys. 2009, $130,224701$.

10. Liu, C.; Shi, J.-W.; Gao, C.; Niu, C. Manganese Oxide-based Catalysts for Low-temperature Selective Catalytic Reduction of $\mathrm{NO}_{x}$ with $\mathrm{NH}_{3}$ : A Review. Appl. Catal., A 2016, 522, 54-69.

11. Sousa, J. P. S.; Pereira, M. F. R.; Figueiredo, J. L. Catalytic Oxidation of NO to $\mathrm{NO}_{2}$ on N-doped Activated Carbons. Catal. Today 2011, 176, 383-387.

12. Li, L.; Shen, Q.; Cheng, J.; Hao, Z. Catalytic Oxidation of NO over $\mathrm{TiO}_{2}$ Supported Platinum Clusters I. Preparation, Characterization and Catalytic Properties. Appl. Catal., B 2010, 93, 259-266.

13. Forzatti, P.; Castoldi, L.; Nova, I.; Lietti, L.; Tronconi, E. $\mathrm{NO}_{\mathrm{x}}$ Removal Catalysis under Lean Conditions. Catal. Today 2006, 117, 316-320.

14. Wang, W.; McCool, G.; Kapur, N.; Yuan, G.; Shan, B.; Nguyen, M.; Graham, U. M.; Davis, B. H.; Jacobs, G.; Cho, K., et al. Mixed-phase Oxide Catalyst Based on Mn-mullite (Sm, Gd) $\mathrm{Mn}_{2} \mathrm{O}_{5}$ for NO Oxidation in Diesel Exhaust. Science 2012, 337, 832-5.

15. Bhatia, D.; McCabe, R. W.; Harold, M. P.; Balakotaiah, V. Experimental and Kinetic Study of NO Oxidation on Model Pt Catalysts. J. Catal. 2009, 266, 106-119. 
16. Liu, J.; Cheng, B.; Yu, J. A New Understanding of the Photocatalytic Mechanism of the Direct Z-scheme g- $\mathrm{C}_{3} \mathrm{~N}_{4} / \mathrm{TiO}_{2}$ Heterostructure. Phys. Chem. Chem. Phys. 2016, 18, 31175-31183.

17. Dong, H.; Zheng, Y.; Hu, P., A DFT Study of Direct Furfural Conversion to 2-methylfuran on the $\mathrm{Ru} / \mathrm{Co}_{3} \mathrm{O}_{4}$ Surface. Phys. Chem. Chem. Phys. 2019, 21, 1597-1605.

18. Yuan, H.; Chen, J.; Guo, Y.; Wang, H.; Hu, P. Insight into the Superior Catalytic Activity of $\mathrm{MnO}_{2}$ for Low-Content $\mathrm{NO}$ Oxidation at Room Temperature. $J$. Phys. Chem. C 2018, 122, 25365-25373.

19. Yuan, H.; Chen, J.; Wang, H.; Hu, P. Activity Trend for Low-Concentration NO Oxidation at Room Temperature on Rutile-Type Metal Oxides. ACS Catal. 2018, 8, 10864-10870.

20. Olsson, L.; Persson, H.; Fridell, E.; Skoglundh, M.; Andersson, B. A Kinetic Study of $\mathrm{NO}$ Oxidation and $\mathrm{NO}_{\mathrm{x}}$ Storage on $\mathrm{Pt} / \mathrm{Al}_{2} \mathrm{O}_{3}$ and $\mathrm{Pt} / \mathrm{BaO} / \mathrm{Al}_{2} \mathrm{O}_{3}$. J. Phys. Chem. B 2001, 105, 6895-6906.

21. Onrubia, J. A.; Pereda-Ayo, B.; De-La-Torre, U.; González-Velasco, J. R. Key Factors in Sr-doped $\mathrm{LaBO}_{3}(\mathrm{~B}=\mathrm{Co}$ or $\mathrm{Mn}$ ) Perovskites for NO Oxidation in Efficient Diesel Exhaust Purification. Appl. Catal., B 2017, 213, 198-210.

22. Yoon, D. Y.; Lim, E.; Kim, Y. J.; Kim, J. H.; Ryu, T.; Lee, S.; Cho, B. K.; Nam, I.-S.; Choung, J. W.; Yoo, S. NO Oxidation Activity of Ag-doped Perovskite Catalysts. J. Catal. 2014, 319, 182-193.

23. Irfan, M. F.; Goo, J. H.; Kim, S. D. $\mathrm{Co}_{3} \mathrm{O}_{4}$ Based Catalysts for NO Oxidation and $\mathrm{NO}_{\mathrm{x}}$ Reduction in Fast SCR Process. Appl. Catal., B 2008, 78, 267-274.

24. Xiao, S.; Zhu, W.; Liu, P.; Liu, F.; Dai, W.; Zhang, D.; Chen, W.; Li, H. CNTs Threaded (001) Exposed $\mathrm{TiO}_{2}$ with High Activity in Photocatalytic NO Oxidation. Nanoscale 2016, 8, 2899-907.

25. Xu, J.; Lu, G.; Guo, Y.; Guo, Y.; Gong, X.-Q. A highly Effective Catalyst of $\mathrm{Co}-\mathrm{CeO}_{2}$ for the Oxidation of Diesel Soot: The Excellent NO Oxidation Activity and $\mathrm{NO}_{\mathrm{x}}$ Storage Capacity. Appl. Catal., A 2017, 535, 1-8.

26. Wang, H. F.; Guo, Y. L.; Lu, G.; Hu, P. NO Oxidation on Platinum Group Metals Oxides: First Principles Calculations Combined with Microkinetic Analysis. $J$. Phys. Chem. C 2009, 113, 18746-18752.

27. Jin, J.; Sun, N.; Hu, W.; Yuan, H.; Wang, H.; Hu, P. Insight into Room-Temperature Catalytic Oxidation of Nitric oxide by $\mathrm{Cr}_{2} \mathrm{O}_{3}$ : A DFT Study. $A C S$ Catal. 2018, 8, 5415-5424.

28. Chorkendorff, I.; Niemantsve, J. W. Concepts of Modern Catalysis and Kinetics. Wiley-VCH: Weinheim, 2003. 
29. Meskine, H.; Matera, S.; Scheffler, M.; Reuter, K.; Metiu, H. Examination of the Concept of Degree of Rate Control by First-principles Kinetic Monte Carlo Simulations. Surf. Sci. 2009, 603, 1724-1730.

30. Hammer, B.; Norskov, J. K. Theoretical Surface Science and CatalysisCalculations and Concepts. Adv. Catal. 2000, 45, 71-129.

31. Smeltz, A. D.; Getman, R. B.; Schneider, W. F.; Ribeiro, F. H. Coupled Theoretical and Experimental Analysis of Surface Coverage Effects in Pt-catalyzed $\mathrm{NO}$ and $\mathrm{O}_{2}$ Reaction to $\mathrm{NO}_{2}$ on $\mathrm{Pt}(111)$. Catal. Today 2008, 136, 84-92.

32. Wang, Z.; Wang, H.-F.; Hu, P. Possibility of Designing Catalysts Beyond the Traditional Volcano Curve: a Theoretical Framework for Multi-phase Surfaces. Chem. Sci. 2015, 6, 5703-5711.

33. Crawford, P.; Hu, P. The Dissociation of Molecularly Adsorbed $\mathrm{CO}$ and $\mathrm{CN}$ over the 4d Transition Metals: A Universal Relationship Between the Reaction Barriers and the Reaction Enthalpies. Surf. Sci. 2007, 601, 341-345.

34. Mulla, S. S.; Chen, N.; Delgass, W. N.; Epling, W. S.; Ribeiro, F. H. $\mathrm{NO}_{2}$ Inhibits the Catalytic Reaction of $\mathrm{NO}$ and $\mathrm{O}_{2}$ over Pt. Catal. Lett. 2005, 100, 267-270.

35. Nakazawa, J.; Smith, B. J.; Stack, T. D. Discrete Complexes Immobilized onto Click-SBA-15 Silica: Controllable Loadings and the Impact of Surface Coverage on Catalysis. J. Am. Chem. Soc. 2012, 134, 2750-9.

36. Grabow, L. C.; Hvolbæk, B.; Nørskov, J. K. Understanding Trends in Catalytic Activity: The Effect of Adsorbate-Adsorbate Interactions for CO Oxidation Over Transition Metals. Top. Catal. 2010, 53, 298-310.

37. Wu, C.; Schmidt, D. J.; Wolverton, C.; Schneider, W. F. Accurate Coverage-dependence Incorporated into First-principles Kinetic Models: Catalytic NO Oxidation on Pt(111). J. Catal. 2012, 286, 88-94.

38. Lausche, A. C.; Medford, A. J.; Khan, T. S.; Xu, Y.; Bligaard, T.; Abild-Pedersen, F.; Nørskov, J. K.; Studt, F. On the Effect of Coverage-dependent Adsorbate-adsorbate Interactions for CO Methanation on Transition Metal Surfaces. J. Catal. 2013, 307, 275-282.

39. Bray, J. M.; Smith, J. L.; Schneider, W. F. Coverage-dependent Adsorption at a Low Symmetry Surface: DFT and Statistical Analysis of Oxygen Chemistry on Kinked Pt(321). Top. Catal. 2013, 57, 89-105.

40. Michaelides, A.; Liu, Z. P.; Zhang, C. J.; Alavi, A.; King, D. A.; Hu, P. Identification of General Linear Relationships between Activation Energies and Enthalpy Changes for Dissociation Reactions at Surfaces. J. Am. Chem. Soc. 2003, $125,3704-5$. 
41. Bligaard, T.; Nørskov, J. K.; Dahl, S.; Matthiesen, J.; Christensen, C. H.; Sehested, J. The Brønsted-Evans-Polanyi Relation and the Volcano Curve in Heterogeneous Catalysis. J. Catal. 2004, 224, 206-217.

42. van Santen, R. A.; Neurock, M.; Shetty, S. G. Reactivity Theory of Transition-metal Surfaces: a Bronsted-Evans-Polanyi Linear Activation Energy-free-energy Analysis. Chem. Rev. 2010, 110, 2005-48.

43. Bray, J. M.; Skavdahl, I. J.; McEwen, J. S.; Schneider, W. F. First-principles Reaction Site Model for Coverage-sensitive Surface Reactions: Pt(111)-O Temperature Programmed Desorption. Surf. Sci. 2014, 622, L1-L6.

44. Getman, R. B.; Schneider, W. F. DFT-Based Coverage-Dependent Model of Pt-Catalyzed NO Oxidation. ChemCatChem 2010, 2, 1450-1460.

45. Medford, A. J.; Shi, C.; Hoffmann, M. J.; Lausche, A. C.; Fitzgibbon, S. R.; Bligaard, T.; Nørskov, J. K. CatMAP: A Software Package for Descriptor-Based Microkinetic Mapping of Catalytic Trends. Catal. Lett. 2015, 145, 794-807.

46. Amberntsson, A.; Fridell, E.; Skoglundh, M. Influence of Platinum and Rhodium Composition on the $\mathrm{NO}_{\mathrm{x}}$ Storage and Sulphur Tolerance of a Barium Based $\mathrm{NO}_{\mathrm{x}}$ Storage Catalyst. Appl. Catal., B 2003, 46, 429-439.

47. Kresse, G.; Furthmüller, J. Efficient Iterative Schemes Forab Initiototal-energy Calculations Using a Plane-Wave Basis Set. Phys. Rev. B: Condens. Matter 1996, 54, 11169-11186.

48. Kresse, G.; Joubert, D. From Ultrasoft Pseudopotentials to the Projector Augmented-wave Method. Phys. Rev. B: Condens. Matter 1999, 59, 1758-1775.

49. Perdew, J. P.; Burke, K.; Ernzerhof, M. Generalized Gradient Approximation Made Simple. Phys. Rev. Lett. 1996, 77, 3865-3868.

50. Blöchl, P. E. Projector Augmented-wave Method. Phys. Rev. B: Condens. Matter 1994, 50, 17953-17979.

51. Monkhorst, H. J.; Pack, J. D. Special Points for Brillouin-zone Integrations. Phys. Rev. B: Condens. Matter 1976, 13, 5188-5192.

52. Alavi, A.; Hu, P.; Deutsch, T.; Silvestrelli, P. L.; Hutter, J. CO Oxidation on Pt(111): An Ab Initio Density Functional Theory Study. Phys. Rev. Lett. 1998, 80, 3650-3653.

53. Michaelides, A.; Hu, P. Catalytic Water Formation on Platinum: A First-Principles Study. J. Am. Chem. Soc. 2001, 123, 4235-4242.

54. Liu, Z. P.; Hu, P. General Rules for Predicting Where a Catalytic Reaction Should Occur on Metal Surfaces: a Density Functional Theory Study of C-H and C-O 
Bond Breaking/making on Flat, Stepped, and Kinked Metal Surfaces. J. Am. Chem. Soc. 2003, 125, 1958-67.

55. Schlegel, H. B. Optimization of Equilibrium Geometries and Transition Structures. J. Comput. Chem. 1982, 3, 214-218.

56. Dumesic, J. A. The microkinetics of heterogeneous catalysis. American Chemical Society: Washington, DC, 1993.

57. Chen, J. F.; Mao, Y.; Wang, H. F.; Hu, P. Reversibility Iteration Method for Understanding Reaction Networks and for Solving Microkinetics in Heterogeneous Catalysis. ACS Catal. 2016, 6, 7078-7087.

58. Feibelman, P. J. Interaction between Adsorbed Chalcogen and Al Atoms on Al(001). Phys. Rev. B: Condens. Matter 1988, 38, 12133-12138.

59. Liu, Z.-P.; Hu, P.; Lee, M.-H. Insight into Association Reactions on Metal Surfaces: Density-functional Theory Studies of Hydrogenation Reactions on Rh(111). The . J. Chem. Phys. 2003, 119, 6282-6289.

60. Liu, Z.-P.; Hu, P. General Rules for Predicting Where a Catalytic Reaction Should Occur on Metal Surfaces: A Density Functional Theory Study of C-H and C-O Bond Breaking/Making on Flat, Stepped, and Kinked Metal Surfaces. J. Am. Chem. Soc. 2003, 125, 1958-1967.

61. Wang, H. F.; Liu, Z. P. Comprehensive Mechanism and Structure-sensitivity of Ethanol Oxidation on Platinum: New Transition-state Searching Method for Resolving the Complex Reaction Network. J. Am. Chem. Soc. 2008, 130, 10996-1004. 


\section{TOC Graphic}

TOFs of NO oxidation calculated with different coverage models

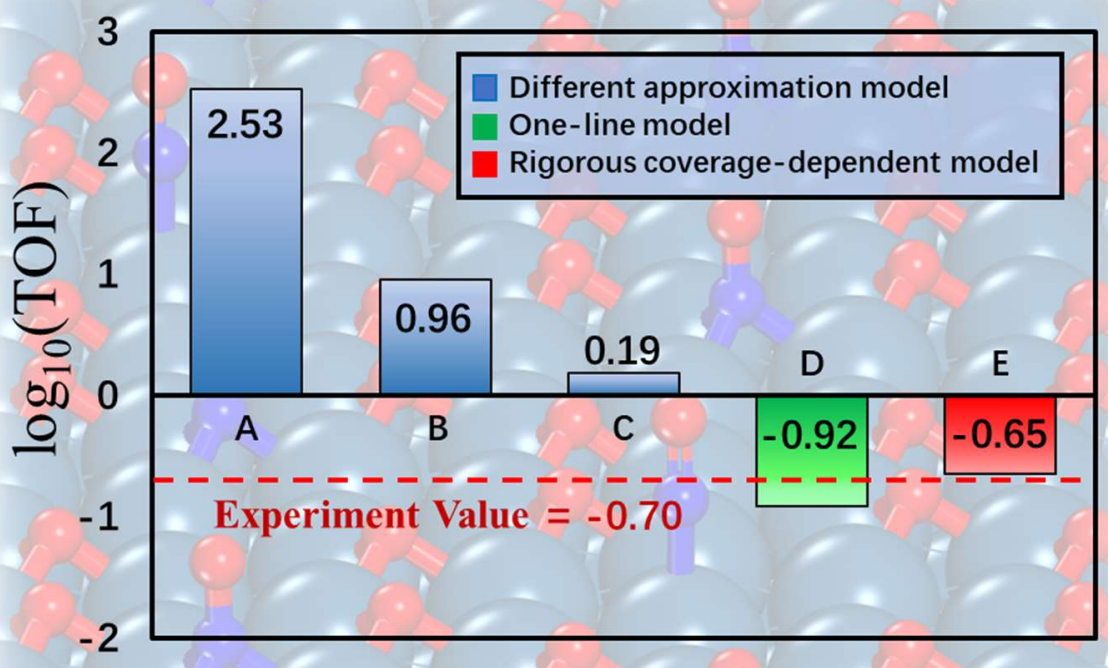

